\title{
Validation of the Direct Nasopharyngeal Sampling Method for Collection of Expired Air in Preterm Neonates
}

\author{
SOPHIE R.D. van der SCHOOR, BARBARA A.E. de KONING, DARCOS L. WATTIMENA, \\ DICK TIBBOEL, AND JOHANNES B. van GOUDOEVER
}

Erasmus MC-Sophia Children's Hospital, Department of Pediatrics, 3015 GJ, Rotterdam, The Netherlands

\begin{abstract}
ABSTR
In clinical studies, the oxidation of ${ }^{13} \mathrm{C}$-labeled substrates to
${ }^{13} \mathrm{CO}_{2}$ and the measurement of the appearance of excess ${ }^{13} \mathrm{CO}_{2}$
in expiratory air has progressed to an increasingly common
method as it is noninvasive and lacks the radiation exposure
associated with the use of ${ }^{14} \mathrm{C}$. The collection of respiratory $\mathrm{CO}_{2}$
currently used occurs via trapping of $\mathrm{CO}_{2}$ in sodium hydroxide
(trapping method), sometimes in conjunction with indirect calo-
rimetry. The aim of the present study was to determine the
accuracy of our direct nasopharyngeal sampling method for the
collection of breath samples in preterm infants compared with
the currently used trapping method. We present a method that
simplifies the collection of breath samples in preterm infants.
Seven preterm infants with a gestational age of 26 -29 wk were
studied on different postnatal days (range, 8 -52 d) while receiv-
ing full enteral feeding. A primed constant 3 -h intragastric
\end{abstract}
During the last three decades, stable isotopes have been used extensively to investigate whole-body protein metabolism in adults, children, and newborns (1-3). To determine the rate of substrate oxidation, the excretion of ${ }^{13} \mathrm{CO}_{2}$ in expired air must be quantified. The rate of oxidation is calculated by multiplying the isotopic enrichment of $\mathrm{CO}_{2}$ in breath by the total rate of $\mathrm{CO}_{2}$ excreted, correcting for the incomplete recovery of ${ }^{13} \mathrm{C}$ during an infusion of $\left[{ }^{13} \mathrm{C}\right]$ bicarbonate (1). This correction factor has to be used to adjust for the fractional recovery of $\mathrm{CO}_{2}(4,5)$. In addition, the $\dot{\mathrm{V}}_{\mathrm{CO}_{2}}$ needs to be measured.

Several methods are used to quantify $\dot{\mathrm{V}}_{\mathrm{CO}_{2}}$, but closedcircuit indirect calorimetry is the most commonly performed method and serves as gold standard for the estimation of $\dot{\mathrm{V}}_{\mathrm{CO}_{2}}$. This procedure requires the patient to breathe via a mouthpiece with the nares occluded or via a hood that catches all expired

Received December 13, 2002; accepted May 14, 2003.

Correspondence: Johannes B. van Goudoever, M.D., Ph.D., Erasmus MC-Sophia Children's Hospital, Department of Pediatrics, Dr. Molewaterplein 60, 3015 GJ, Rotterdam, The Netherlands; e-mail: j.vangoudoever@erasmusmc.nl

Supported by The Sophia Foundation of Scientific Research (Kröger Foundation), the Royal Netherlands Academy of Arts and Science (Ter Meulen Fund), and the Nutricia Research Foundation.

DOI: 10.1203/01.PDR.0000099792.66562.7E infusion of $\left[{ }^{13} \mathrm{C}\right]$ bicarbonate was given, and breath samples were collected by means of direct nasopharyngeal sampling and by a sodium hydroxide trap simultaneously. Breath $\mathrm{CO}_{2}$ isotopic enrichments rose rapidly to reach a plateau by $120 \mathrm{~min}$ with $<5 \%$ variation of plateau in both methods. ${ }^{13} \mathrm{CO}_{2}$ breath isotopic enrichments obtained by the direct nasopharyngeal sampling method correlated highly $\left(r^{2}=0.933 ; p<0.0001\right)$ with the trapping method. The Bland-Altman analysis showed no significant variability between the two methods and demonstrated that the $95 \%$ confidence interval is within $\pm 4.68 \delta \%$. These findings validate the simple method of direct nasopharyngeal sampling of expired air in neonates. (Pediatr Res 55: 50-54, 2004)

\section{Abbreviation}

$\dot{\mathbf{V}} \mathrm{Co}_{2}$, total carbon dioxide production
$\mathrm{CO}_{2}$ (6). However, interpretation of the results obtained from indirect calorimetry may be difficult in particular. For instance, results are difficult to interpret when there is an unmeasured loss of expired gasses because of the use of uncuffed leaking endotracheal tubes in mechanically ventilated neonates (7). In addition, there is an increased possibility of error in the indirect calorimeter determination of oxygen consumption and $\dot{\mathrm{V}}_{2}$ with the low volumes of respiratory gas exchanged in small neonates (8) and the higher fraction of inspired oxygen used in critically ill patients (9). This error is of such a significant degree that the use of indirect calorimetry is not recommended in patients receiving more than 0.60 fraction of inspired oxygen (10).

Another method for measuring $\dot{\mathrm{V}}_{\mathrm{CO}_{2}}$ involves the infusion of a ${ }^{14} \mathrm{C}$-labeled substrate and the measurement of its specific activity and the rate of excretion of ${ }^{14} \mathrm{CO}_{2}$ in breath for a period at isotopic steady-state (11). However, the use of radioactive isotopes in children is prohibited.

Numerous studies described the use of dilution of ${ }^{13} \mathrm{CO}_{2}$ during the infusion of $\left[{ }^{13} \mathrm{C}\right]$ bicarbonate to calculate $\mathrm{CO}_{2}$ production, which avoids the quantification of total expired air $(4,12)$. However, this tracer technique uses a relatively com- 
plicated method to collect expired air. Breath samples must be collected using a closely fitted facemask and an inlet-outlet system with a low dead volume. Thereafter, the collected expired air has to pass through an all-glass spiral condenser containing sodium hydroxide. After liberating $\mathrm{CO}_{2}$ by adding phosphoric acid to the solution, the $\mathrm{CO}_{2}$ can be stored in a septum-capped tube until analysis (13). During all these procedures to liberate $\mathrm{CO}_{2}$, the fraction of ${ }^{13} \mathrm{CO}_{2}$ might be decreased, resulting in an underestimation of the substrate oxidation.

To collect breath samples from preterm infants in a suitable manner, we applied the direct nasopharyngeal sampling technique previously described by Perman et al. (14). This method has been used in older children for the noninvasive diagnosis of sucrose or lactose malabsorption by a hydrogen breath test, and in preterm infants for the collection of expiratory air after administration of ${ }^{13} \mathrm{C}$-labeled substrates (14-16). However, in preterm infants, the direct nasopharyngeal sampling method has never been validated for the use in substrate oxidation studies. The direct sampling approach offers the advantage of being simple and not time-consuming, making it appropriate for use in preterm infants in combination with $\left[{ }^{13} \mathrm{C}\right]$ bicarbonate stable isotope dilution technique to estimate the $\mathrm{CO}_{2}$ production. Validation of such a method would provide a technique that could be used in a variety of clinical investigations in neonates and children.

The purpose of this study was to determine whether the direct nasopharyngeal sampling technique for the collection of expired air could be used to estimate $\mathrm{CO}_{2}$ production in preterm infants. We validated this technique against the method using $\mathrm{CO}_{2}$ trapping in sodium hydroxide for collection of expiratory air after $\left[{ }^{13} \mathrm{C}\right]$ bicarbonate infusion in preterm infants.

\section{METHODS}

Subjects. Subjects included seven preterm infants admitted to the neonatal intensive care unit of the Erasmus MC-Sophia Children's Hospital. The study protocol was reviewed and approved by the Erasmus-MC Institutional Review Board, and written and informed consent was obtained from the parents of the preterm infants.

Direct nasopharyngeal sampling method and trapping method. The collection of expired air was obtained by two different methods, i.e. the direct nasopharyngeal sampling method and the trapping method. In the direct nasopharyngeal sampling technique for the collection of expired air, we used a 6F gastric tube (6 Ch Argyle; Sherwood Medical, Tullamore, Ireland) as a collection device, which was placed carefully for 1 to $1.5 \mathrm{~cm}$ into the nasopharynx. When the infant received supplemental oxygen by nasal prong, the oxygen air had to pass a soda-lime filter (Erich Jaeger GmbH \& Co. KG, Wurzburg, Germany) before entering the nasopharynx to supply $\mathrm{CO}_{2}$-free air. While observing the patient's normal breathing pattern, the examiner repeatedly aspirated $1 \mathrm{~mL}$ of each tidal volume late in the expiratory phase from the nasal prong connected to a $10-\mathrm{mL}$ plastic syringe until $10 \mathrm{~mL}$ was obtained. Aliquots were transferred by syringe to a $10-\mathrm{mL}$ Va- cutainer (Van Loenen Instruments, Zaandam, The Netherlands).

The trapping method has been described for $\dot{\mathrm{V}}_{\mathrm{CO}_{2}}$ measurements in neonates $(13,17)$. In this method, breath samples are collected via a closely fitted facemask or canopy, which is placed around the head and chest of the neonate. The baby's head and neck were placed under the transparent Perspex canopy, and a partial seal is created by tucking the attached flexible material beneath the body and mattress to prevent any air leaks. We used a canopy as is used for indirect calorimetry studies in infants (18). An inlet-outlet system with a low dead volume is used to avoid dilution of the carbon dioxide $<1.5$ $2.0 \%$. Next, the collected expired air has to pass a sample of air leaving the ventilated hood through an all-glass spiral condenser, containing $10 \mathrm{~mL}$ of $1 \mathrm{M}$ sodium hydroxide (Merck, Darmstadt, Germany). After liberating $\mathrm{CO}_{2}$ by adding phosphoric acid (Merck) to the solution, the $\mathrm{CO}_{2}$ can be stored in septum-capped tubes until analysis.

Validation of the collection method. To demonstrate that the isotopic enrichment in the expired air collected by the direct nasopharyngeal sampling method showed a consistent relationship and to show that this collection of expired air is a reliable technique, comparison with the trapping method was performed. Validation of direct nasopharyngeal sampling technique and the trapping method was achieved by simultaneously obtaining duplicate paired samples of expired air according to both methods in seven clinically stable preterm infants without ventilatory support.

Tracer protocol. After baseline expired breath samples were obtained according to both methods (Fig. 1), a primed (10.02 $\mu \mathrm{mol} / \mathrm{kg}), 3-\mathrm{h}$ continuous intragastric infusion $(10.02$ $\left.\mu \mathrm{mol} \cdot \mathrm{kg}^{-1} \cdot \mathrm{h}^{-1}\right)$ of sterile pyrogen-free sodium $\left[1-{ }^{13} \mathrm{C}\right]$ bicarbonate $\left(99 \mathrm{~mol} \%{ }^{13} \mathrm{C}\right.$; Cambridge Isotopes, Woburn, MA, U.S.A.) was administered. Five sets of duplicate $\mathrm{CO}_{2}$ breath samples were collected at 15-min intervals during the last hour of infusion by using both sampling techniques. Breath $\mathrm{CO}_{2}$ isotopic enrichment was plotted against time, and the plateau defined according to the convention of taking four or more consecutive points with a coefficient of variation of $<5 \%$.

Analytical methods. Isotopic enrichment of expired $\mathrm{CO}_{2}$ was measured by monitoring ions at $\mathrm{m} / \mathrm{e} 44$ and 45 with a continuous flow isotope ratio mass spectrometer (ABCA; Europa Scientific, Van Loenen Instruments, Leiden, The Netherlands) (19). The ratio of the signals from the ionized species ${ }^{13} \mathrm{CO}_{2}$ and ${ }^{12} \mathrm{CO}_{2}$ each focused on one of the dual spectrome-

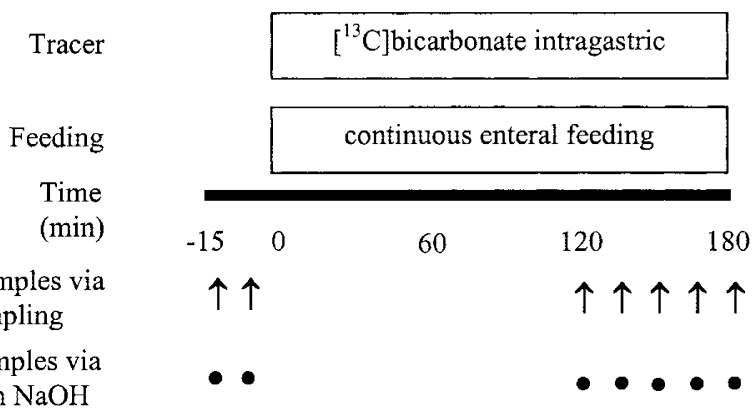

Figure 1. Schematic overview of study protocol. 
ters is recorded and compared with the natural abundance of $\mathrm{CO}_{2}$ gas of known isotopic composition relative to the standard Pee Dee Belemnite (PDB). The results of this differential measurement are expressed as the delta per mille $(\delta \%)$ difference between the ${ }^{13} \mathrm{CO}_{2}{ }^{12} \mathrm{CO}_{2}$ ratio of the sample and standard (20).

$$
\delta^{13} \mathrm{C}(\% \mathrm{o})=\frac{R_{\mathrm{u}}-R_{\mathrm{s}}}{R_{\mathrm{s}}} \times 1000
$$

where $R_{\mathrm{u}}$ is the difference between the ${ }^{13} \mathrm{CO}_{2}{ }^{12} \mathrm{CO}_{2}$ ratio of the sample, and $R_{\mathrm{s}}$ is the difference between the ${ }^{13} \mathrm{CO}_{2} /{ }^{12} \mathrm{CO}_{2}$ ratio of the standard.

Steady-state values were obtained by determining the average $\mathrm{CO}_{2}$ isotopic enrichment after reaching plateau as previously described (21). $\mathrm{RaCO}_{2}$ was calculated using the standard steady-state equation (22):

$$
\mathrm{RaCO}_{2}=i_{\mathrm{B}} \times\left[\left(I E_{\mathrm{I}} / I E_{\mathrm{B}}\right)-1\right]
$$

where $i_{\mathrm{B}}$ is the infusion rate of sodium $\left[{ }^{13} \mathrm{C}\right]$ bicarbonate $\left(\mu \mathrm{mol} \cdot \mathrm{kg}^{-1} \cdot \mathrm{h}^{-1}\right), I E_{\mathrm{I}}$ is the enrichment (mole percent excess) of $\left[{ }^{13} \mathrm{C}\right]$ bicarbonate in the bicarbonate infusate, and $I E_{\mathrm{B}}$ is the ${ }^{13} \mathrm{CO}_{2}$ enrichment in expiratory air at plateau during the sodium $\left[{ }^{13} \mathrm{C}\right]$ bicarbonate infusion (mole percent excess).

Statistics. All values are expressed in mean \pm SD. Statistical analyses were performed by ANOVA, $t$ test, and Pearson correlation. Significance was determined as $p<0.05$. BlandAltman analysis was performed to test the variability between the two sampling methods (23).

\section{RESULTS}

All infants were appropriate for gestational age (median gestational age, 28 wk; range, 26-29 wk; Table 1). Seven patients who breathed spontaneously were studied; six of them received supplemental oxygen by a nasal prong. All infants were clinically stable at the time of the study. The median body weight at the time of study period was $1.2 \mathrm{~kg}$ (range, 1.0-1.5 $\mathrm{kg}$ ), and the median postnatal age was $28 \mathrm{~d}$ (range, 8-52 d).

The estimated $\mathrm{CO}_{2}$ production was $37.04 \pm 5.99$ $\mathrm{mmol} \cdot \mathrm{kg}^{-1} \cdot \mathrm{h}^{-1}$ ). Isotopic steady-state was achieved during sodium $\left[{ }^{13} \mathrm{C}\right]$ bicarbonate infusion with a coefficient of variation of $4.1 \%$ in the direct sampling method and $4.8 \%$ in the trapping method (Fig. 2). More importantly, the delta per mille difference determined from the direct nasopharyngeal sampling method correlated highly $\left(r^{2}=0.933 ; p<0.0001\right)$ with the delta per mille difference obtained by the trapping technique.
Furthermore, Bland-Altman analysis (Fig. 3) demonstrated agreement between the two methods to within $\pm 4.68 \delta \%$, i.e. $95 \%$ confidence interval.

\section{DISCUSSION}

The present study describes a methodology for the collection of expired air in preterm infants after administration of ${ }^{13} \mathrm{C}$ labeled material. In preterm neonates, isotopic steady-state of ${ }^{13} \mathrm{CO}_{2}$ in breath obtained by our direct nasopharyngeal sampling technique during a $\left[{ }^{13} \mathrm{C}\right]$ bicarbonate infusion agreed closely with the isotopic steady-state obtained with the trapping technique during a $\left[{ }^{13} \mathrm{C}\right]$ bicarbonate infusion. This is demonstrated by the highly significant correlation between the measured values acquired from both methods. Therefore, in neonates the direct nasopharyngeal sampling technique can be used for the measurement of $\mathrm{CO}_{2}$ isotopic enrichment, which is necessary for estimation of $\dot{\mathrm{V}}_{\mathrm{CO}_{2}}$ and the quantification of oxidation of labeled substrates.

To determine the accuracy and precision of our technique in each individual subject in comparison with the trapping method we used the Bland-Altman analysis. Furthermore, by using this analysis we could assess the variability between the two methods (23). As shown in Figure 3, the 95\% confidence interval of the two methods vary within an acceptable \pm 4.68 $\delta \%$. In other words, there is less then $5 \%$ probability that the two methods differ more than this amount.

Although we validated our direct sampling method only in nonventilated infants, we speculate that this technique will work in ventilated infants. Instead of sampling directly from the nasopharynx, expired air has to be withdrawn from the ventilation tube. The clinical applications of the direct sampling technique for the collection of breath are extensive, because whole-body flux and oxidation rates of nutrients can be quantified in adults and infants from primed constant infusion studies using ${ }^{13} \mathrm{C}$-labeled substrates with the collection of expired air (1-3). The methodology for measuring in vivo oxidation of substrates with the use of ${ }^{13} \mathrm{C}$-labeled material in clinical studies has been developed with the use of isotope ratio mass spectrometry analysis. The direct sampling method can also be used in breath tests for the noninvasive diagnosis of sucrose or lactose malabsorption and gastric emptying.

The excretion of labeled $\mathrm{CO}_{2}$ in breath after administration of ${ }^{13} \mathrm{C}$-labeled substrates is a function of the physical variables involved in $\mathrm{CO}_{2}$ metabolism, the kinetics of metabolism, and the delay associated with the passage through the whole-body

\begin{tabular}{|c|c|c|c|c|c|c|}
\hline Patient & Gender & $\begin{array}{c}\text { Birth weight } \\
(\mathrm{kg})\end{array}$ & $\begin{array}{c}\text { Gestational age } \\
\text { (wk) }\end{array}$ & $\begin{array}{c}\text { Study weight } \\
(\mathrm{g})\end{array}$ & $\begin{array}{l}\text { Postnatal age } \\
\text { (d) }\end{array}$ & Ventilation \\
\hline 1 & $\mathrm{~F}$ & 0.62 & 29 & 1.06 & 52 & none \\
\hline 2 & M & 0.96 & 26 & 1.48 & 52 & nasal prong \\
\hline 3 & $\mathrm{~F}$ & 1.11 & 28 & 1.38 & 29 & nasal prong \\
\hline 4 & $\mathrm{~F}$ & 0.46 & 27 & 0.60 & 18 & nasal prong \\
\hline 5 & $\mathrm{~F}$ & 0.88 & 28 & 0.98 & 21 & nasal prong \\
\hline 6 & M & 1.29 & 28 & 1.19 & 16 & nasal prong \\
\hline 7 & M & 0.99 & 27 & 1.35 & 36 & nasal prong \\
\hline Median & & 1.01 & 28 & 1.18 & 28 & \\
\hline
\end{tabular}

Table 1. Clinical characteristics 


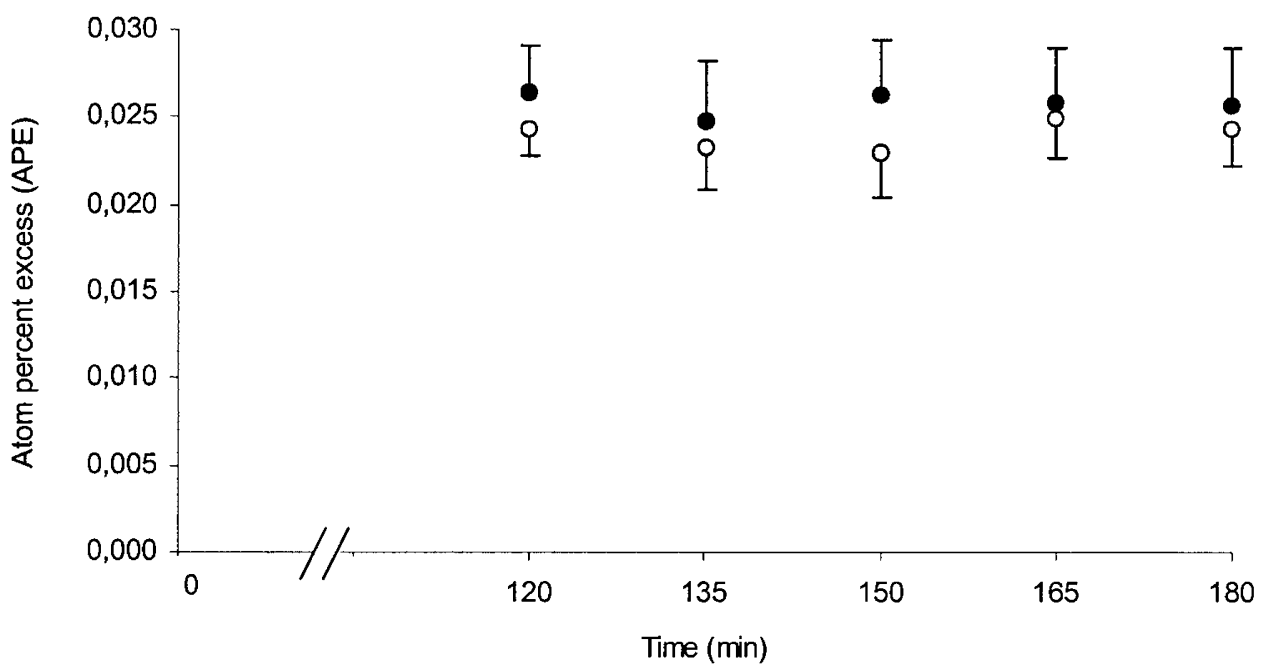

Figure 2. Steady-state isotopic enrichment of $\mathrm{CO}_{2}$ in breath collected by the direct nasopharyngeal sampling method (dark circles) and collected by the trapping method (white circles) after a primed-constant intragastric $\left[{ }^{13} \mathrm{C}\right]$ bicarbonate infusion. An isotopic steady-state was achieved by 120 min with less than $5 \%$ variation of the plateau in both methods.

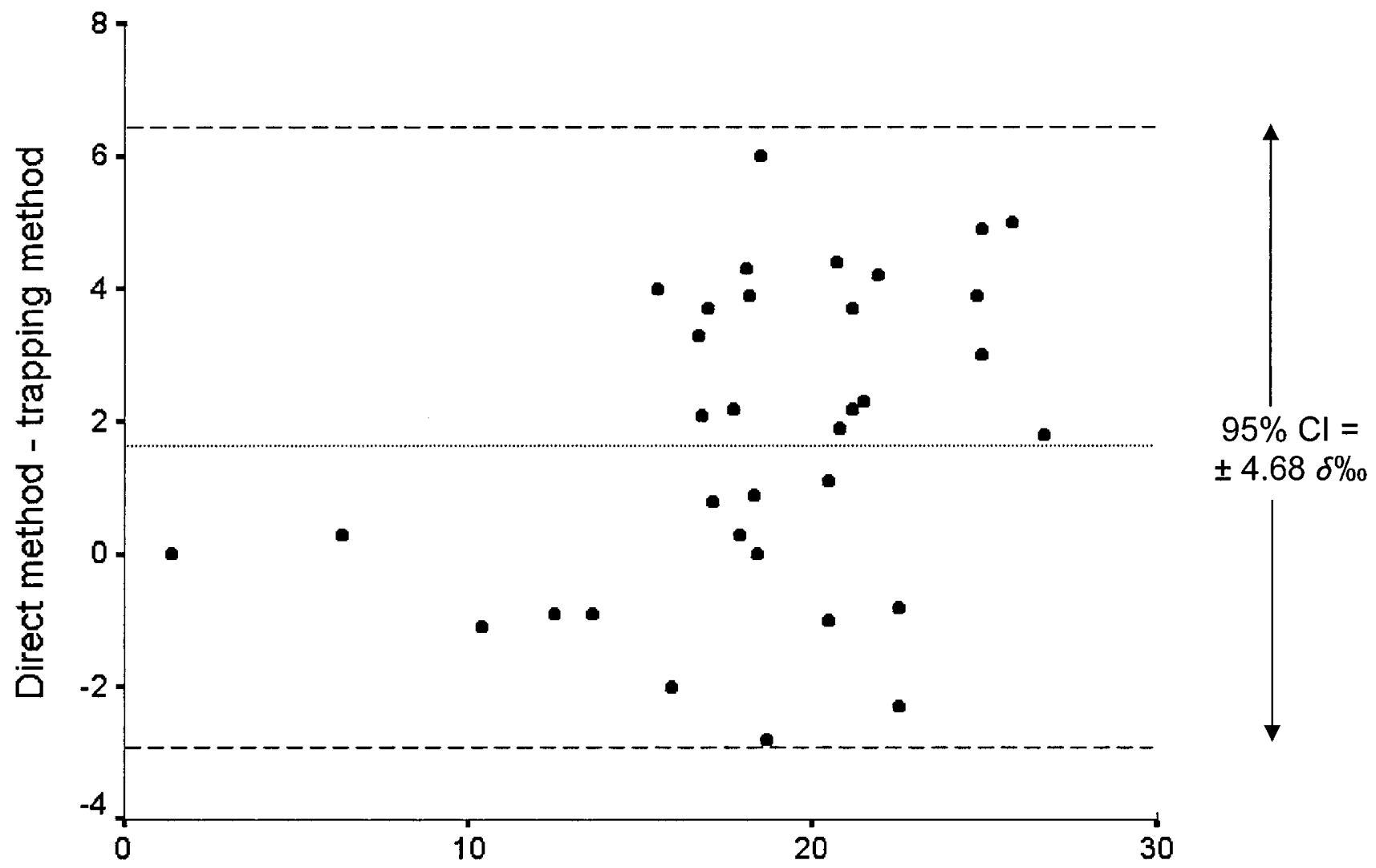

\section{Average (direct method $x$ trapping method)}

Figure 3. Bland-Altman analysis showing the difference between the direct nasopharyngeal sampling method and the trapping method measurements of ${ }^{13} \mathrm{CO}_{2}$ enrichment in breath is in agreement to within $\pm 4.68 \delta \%$. $C I$ indicates confidence interval.

bicarbonate pool before its expiration in the breath (24). For example, the labeled $\mathrm{CO}_{2}$ is temporarily retained in the bicarbonate pool of the bone, in larger organic molecules, and in smaller amounts in feces, sweat, and urine (24). That this bicarbonate pool is limited is shown by an almost complete recovery of $\mathrm{CO}_{2}$ during an extended infusion $(24-48 \mathrm{~h})$ and collection of expired air (25). In short-lasting studies in neonates, the $\mathrm{CO}_{2}$ retention varies between 70 and $84 \%$ and is correlated with the energy intake, metabolic rate, and $\dot{\mathrm{V}}_{\mathrm{CO}_{2}}$ (5). Therefore, to determine the rate of oxidation of a labeled substrate, a correction factor is commonly used in the calculations (5). However, in previous studies in preterm infants 
without signs of infection or respiratory distress, we have shown that the correction factor can be left out assuming a constant $\dot{\mathrm{V}} \mathrm{CO}_{2}$ for a few hours and by the use of a sequential $\left[{ }^{13} \mathrm{C}\right]$ bicarbonate and ${ }^{13} \mathrm{C}$-labeled substrate infusion $(13,17)$. Therefore, our direct sampling technique can be used very well to collect expired $\mathrm{CO}_{2}$ for mass spectrometric analysis.

\section{CONCLUSIONS}

We conclude that the presently described direct nasopharyngeal sampling method for the collection of expired air in preterm neonates is as good as other previously described breath collection methods for the calculation of substrate oxidation. This method is simple to use, and should provide new opportunities to study metabolism of various substrates in preterm infants, children, and adults.

Acknowledgments. The authors thank prof.dr. H.A. Büller for helpful comments and review of the manuscript. We also thank the parents who consented for their babies to participate in the study.

\section{REFERENCES}

1. Matthews DE, Motil KJ, Rohrbaugh DK, Burke JF, Young VR, Bier DM 1980 Measurement of leucine metabolism in man from a primed, continuous infusion of L- $\left[1-{ }^{13} \mathrm{C}\right]$ leucine. Am J Physiol 238:E473-E479

2. Denne SC, Kalhan SC 1987 Leucine metabolism in human newborns. Am J Physiol 253:E608-E615

3. Van Goudoever JB, Sulkers EJ, Halliday D, Degenhart HJ, Carnielli VP, Wattimena JL, Sauer PJ 1995 Whole-body protein turnover in preterm appropriate for gestational age and small for gestational age infants: comparison of $\left[{ }^{15} \mathrm{~N}\right]$ glycine and $\left[1-{ }^{13} \mathrm{C}\right]$ leucine administered simultaneously. Pediatr Res 37:381-388

4. Kien CL 1989 Isotopic dilution of $\mathrm{CO}_{2}$ as an estimate of $\mathrm{CO}_{2}$ production during substrate oxidation studies. Am J Physiol 257:E296-E298

5. Van Aerde JE, Sauer PJ, Pencharz PB, Canagarayar U, Beesley J, Smith JM, Swyer PR 1995 The effect of energy intake and expenditure on the recovery of ${ }^{13} \mathrm{CO}_{2}$ in the parenterally fed neonate during a 4-hour primed constant infusion of $\mathrm{NaH}^{13} \mathrm{CO}_{3}$. Pediatr Res 19:806-810

6. Ferrannini E 1988 The theoretical bases of indirect calorimetry: a review. Metabolism $37: 287-301$
7. Forsyth JS, Crighton A 1995 Low birthweight infants and total parenteral nutrition immediately after birth. I. Energy expenditure and respiratory quotient of ventilated and non-ventilated infants. Arch Dis Child Fetal Neonatal Ed 73:F4-F7

8. Bauer K, Pasel K, Uhrig C, Sperling P, Versmold H 1997 Comparison of face mask, head hood, and canopy for breath sampling in flow-through indirect calorimetry to measure oxygen consumption and carbon dioxide production of preterm infants $<1500$ grams. Pediatr Res 41:139-144

9. Ultman JS, Bursztein S 1981 Analysis of error in the determination of respiratory gas exchange at varying $\mathrm{FiO}_{2}$. J Appl Physiol 50:210-216

10. Mayfield SR 1991 Technical and clinical testing of a computerized indirect calorimeter for use in mechanically ventilated neonates. Am J Clin Nutr 54:30-34

11. Classic KL, Schenk WF, Haymond MW 1986 Radiobiological half-lives for carbon-14 and hydrogen-3 leucine in man. Proc 4th Int Radiopharm Dosimetry Sym 681-687

12. Spear ML, Darmaun D, Sager BK, Parsons WR, Haymond MW 1995 Use of $\left[{ }^{13} \mathrm{C}\right]$ bicarbonate infusion for measurement of $\mathrm{CO}_{2}$ production. Am J Physiol 268:E1123-E1127

13. Van Goudoever JB, Sulkers EJ, Kalhan SC, Sauer PJ 1993 Glucose metabolism in a term infant with transient hyperinsulinism and high carbohydrate intake. Eur J Pediatr 152:343-347

14. Perman JA, Barr RG, Watkins JB 1978 Sucrose malabsorption in children; a noninvasive diagnosis by interval breath hydrogen determination. J Pediatr 93:17-22

15. Veereman-Wauters G, Ghoos Y, Van der Schoor S, Maes B, Hebbalkar N, Devlieger $\mathrm{H}$, Eggermont E 1996 The ${ }^{13} \mathrm{C}$-octanoic acid breath test: a noninvasive technique to assess gastric emptying in preterm infants. J Pediatr Gastroenterol Nutr 23:111-117

16. Van Dijk-Van Aalst K, Van den Driessche M, Van der Schoor S, Schiffelers S, van't Westeinde T, Ghoos Y, Veereman-Wauters G $2001{ }^{13} \mathrm{C}$ mixed triglyceride breath test: a noninvasive method to assess lipase activity in children. J Pediatr Gastroenterol Nutr 32:579-585

17. Van Goudoever JB, Colen T, Wattimena JL, Huijmans JG, Carnielli VP, Sauer PJ 1995 Immediate commencement of amino acid supplementation in preterm infants: effect on serum amino acid concentrations and protein kinetics on the first day of life. J Pediatr 127:458-465

18. Kingdon CC, Mitchell F, Bodamer OA, Williams AF 2000 Measurement of carbon dioxide production in very low birth weight babies. Arch Dis Child Fetal Neonatal Ed 83:F50-F55

19. Zuijdgeest-van Leeuwen SD, Van den Berg JW, Wattimena JL, Van der Gaast A, Swart GR, Wilson JH, Dagnelie PC 2000 Lipolysis and lipid oxidation in weightlosing cancer patients and healthy subjects. Metabolism 49:931-936

20. Craig H 1957 Isotopic standards for $\mathrm{C}$ and $\mathrm{O}$ and correction factors for massspectrometric analysis of $\mathrm{CO}_{2}$. Geochim Cosmochim Acta 12:133-149

21. Jahoor F, Burrin DG, Reeds PJ, Frazer M 1994 Measurement of plasma protein synthesis rate in infant pig: an investigation of alternative tracer approaches. Am J Physiol 267:R221-R227

22. Tserng K, Hay WJ 1983 Calculation of substrate turnover rate in stable isotope tracer studies. Am J Physiol 245:E308-E311

23. Bland JM, Altman DG 1986 Statistical methods for assessing agreement between two methods of clinical measurement. Lancet 1:307-310

24. Winchell HS, Wiley K 1970 Considerations in analysis of breath ${ }^{14} \mathrm{CO}_{2}$ data. J Nucl Med 11:708-710

25. Elia M, Fuller NJ, Murgatroyd PR 1992 Measurement of bicarbonate turnover in humans: applicability to estimation of energy expenditure. Am J Physiol 263:E676E687 